\title{
Application of response surface methodology for color removing from dyeing effluent using de-oiled activated algal biomass
}

\author{
Samar A. El-Mekkawi ${ }^{1^{*}}\left(\mathbb{D}\right.$, Rehab A. Abdelghaffar ${ }^{2}$, Fatma Abdelghaffar ${ }^{2}$ and S. A. Abo El-Enin ${ }^{1}$
}

\begin{abstract}
Background: Conservation of the ecosystem is a prime concern of human communities. Industrial development should adopt this concern. Unfortunately, various related activities release lots of noxious materials concurrently with significant leakage of renewable resources. This work presents a new biosorbent activated de-oiled microalgae, Chlorella vulgaris, (AC) for biosorption of Acid Red 1 (AR1) from aqueous solution simulated to textile dyeing effluent. The biosorption characteristics of AC were explored as a function of the process parameters, namely $\mathrm{pH}$, time, and initial dye concentration using response surface methodology (RSM).

Results: Optimization is carried out using the desirability approach of the process parameters for maximum dye removal\%. The ANOVA analysis of the predicted quadratic model elucidated significant model terms with a regression coefficient value of $0.97, F$ value of 109.66, and adequate precision of 34.32 that emphasizes the applicability of the model to navigate the design space. The optimization depends on the priority of minimizing the time of the process to save energy and treating high concentrated effluent resulted in removal \% up to $83.5 \%$. The chemical structure and surface morphology of $\mathrm{AC}$, and the dye-loaded biomass (AB) were characterized by Fourier transform infrared spectroscopy (FTIR), scanning electron microscopy (SEM), energy-dispersive X-ray analysis (EDX), and transmission electron microscope (TEM). The activation process transforms the biomass surface into a regular and small homogeneous size that increases the surface area and ultimately enhances its adsorption capacity

Conclusion: The optimization of the process parameters simultaneously using RSM performs a high-accurate model which describes the relationship between the parameters and the response through minimum number of experiments. This study performed a step towards an integrated sustainable solution applicable for treating industrial effluents through a zero-waste process. Using the overloaded biomass is going into further studies as micronutrients for agricultural soil.
\end{abstract}

Keywords: De-fated microalgae, Activated biosorbent, Effluent treatment, Dye removal, Desirability function

\section{Background}

The demand for industrial products is accelerating because of population growth (Heffron et al. 2020). Dyes are necessary for coloring and finishing the final products' packages of various industries such as textiles, leather,

\footnotetext{
*Correspondence: samarelmekkawi@hotmail.com

${ }^{1}$ Chemical Engineering and Pilot Plant Department, Engineering Research Division, National Research Centre, P.O. 12622, Giza, Egypt Full list of author information is available at the end of the article
}

cosmetics, and food (Ribeiro and Veloso 2021; Tang et al. 2021). As a consequence of the variety of industrial products, enormous amounts of effluent discharge contaminated with dyes require treatment (Abdulrazzaq et al. 2021, Wang et al. 2021). The textile industry uses around $30 \%$ of synthetic dyes. This industry is developed globally, growing 1 trillion dollars, employing 35 million employees, and contributing $7 \%$ of the total world exports (Lellis et al. 2019; de Oliveira Neto 2021). Despite its high attention, this industry is an extremely global polluter as 
a consequence of the large amounts of the drained dyes in the textile effluents (da Silva et al. 2021).

The discharge of the untreated effluents overloaded with dyes into the water bodies is eco-destructive (Kishor et al. 2021). It prevents light penetration through water, causing a reduction in the photosynthesis rate of phytoplankton which affects the aquatic biota (Berradi et al. 2019; Watari et al. 2020). The dyes also act as carcinogenic, toxic, and mutagenic agents (Liang et al. 2020). It is rather difficult to treat dye effluent for such dyes of aromatic molecular structure as acid, basic, direct, and reactive dyes. The complex aromatic structure enhances molecular stability and tolerates biological degradability (Zhang et al. 2020).

Environmental regulations have grown more stringent all over the world. Therefore, the dye effluent should be treated carefully before discharge. There are several methods for color removal as coagulation and flocculation (Abdulrazzaq et al. 2021), membrane filtration (Mansor et al. 2020), foam separation (Soylu et al. 2020), and chemical precipitation (Shen et al. 2019). A novel approach based on activated carbon is the potential for dye removal. Some limitations are mentioned for this approach, such as the shortage of renewable resources and the difficulties in the regeneration of the substrate. The global demand for the production of activated carbon using alternative environmentally friendly resources has annually increased (Liu et al. 2020; Suhas et al. 2021).

Lately, the use of renewable raw materials, plenteously available and inexpensive to produce valuable activated carbon has attracted a lot of attention (Taer et al. 2021). Thermal activation can be done in two stages including carbonization and subsequently activation. Dehydration of the samples enhances the yield of carbonization as a consequence of the sufficient removal of the volatile compounds (Suganya et al. 2020).

Several microorganisms like yeasts, bacteria, fungi, and algae are used to develop cheaper alternatives (Cheng et al. 2020; Semião et al. 2020). In this respect, microalgae have high sorption capacity and high binding affinity due to their functional groups, such as amino, sulfate, phosphate, carboxyl, and hydroxyl groups (Khorasani and Shojaosadati 2019). The other merits of using microalgae as a feedstock are the rapid growth rate due to its high photosynthetic efficiency, and less land area required without competing with the food crops (Chew et al. 2021).

The efficiency of the biosorption process depends on several parameters like the concentration of dyes as the pollutant, $\mathrm{pH}$ solution, and the processing time (Adeogun et al. 2019). Optimization of these parameters requires a large number of experiments to evaluate the effect of each one. Therefore, response surface methodology
(RSM) is the best route to optimize the three parameters simultaneously and investigate the interaction between the parameters (Khalifa et al. 2019). The RSM based on the central composite design (CCD) ensures the best fitting of the predicted model in case of significant curvature of the relation between the model parameters and the resulted response (Asfaram et al. 2016).

The previously reported researches tackled microorganisms as biosorber in their live form or dried biomass. Asfaram et al. (2016) studied the potentiality of isolated Yarrowia lipolytica isf7 to remove malachite green from culture. The optimum dye removal \% was $80 \%$ at pH 7, temperature $25^{\circ} \mathrm{C}, 24 \mathrm{~h}$, and $35 \mathrm{mg} / \mathrm{L}$ initial dye concentration with a sharp decrease in dye removal for alkaline $\mathrm{pH}$ above 7.5 and acidic $\mathrm{pH}$ below 5 . YeddouMezenner (2010) performed a kinetic study about the effect of waste $P$. mutilus dry biomass $(50-215 \mu \mathrm{m})$ on removing Basic Blue 41 dye from aqueous solutions. The maximum percent removal was $65 \%$ at initial concentration $50 \mathrm{mg} / \mathrm{L}, \mathrm{pH} 9-8,30^{\circ} \mathrm{C}$, and $60 \mathrm{~min}$.

To the best of our knowledge, there are no published reports on the application of the de-oiled activated carbon from algae in biosorption. Based on the integrated process to utilize the extracted oil out of Chlorella vulgaris in different industries, the residual biomass is used as an effective biosorbent via activation. The potentiality of the overloaded biosorbent as a nano-nutrient for agriculture is suggested for further research.

In this study, the biosorption of Acid red1 (AR1) dye from aqueous solutions using activated de-oiled microalgae dried biomass was studied. The $\mathrm{pH}$ of the effluent stream, the contact time, and the dye concentration as three parameters affecting the dye removal from a simulated dye effluent were studied and analyzed using CCD in RSM. Finally, a prediction model for the optimum dye removal percentage was derived considering the priority of minimizing the contact time at maximum concentration. Fourier transform infrared spectroscopy (FTIR) analysis was performed to elucidate the functional groups involved in the adsorption process. The change of the amorphous structure of biosorbent was to be investigated using scanning electron microscopy (SEM) analysis, and the elemental analysis was to be detected by energy-dispersive $\mathrm{X}$-ray analysis (EDX).

\section{Methods \\ Material}

Dry algal biomass of Chlorella vulgaris was acquired by the Algal Biotechnology Unit, National Research Center, Egypt. The microalga was defatted using ethanol in a ratio of 1:6 W/V. The extracted oil was used in other research work for biodiesel production, while the residual biomass (RB) was collected to examine its potentiality as 


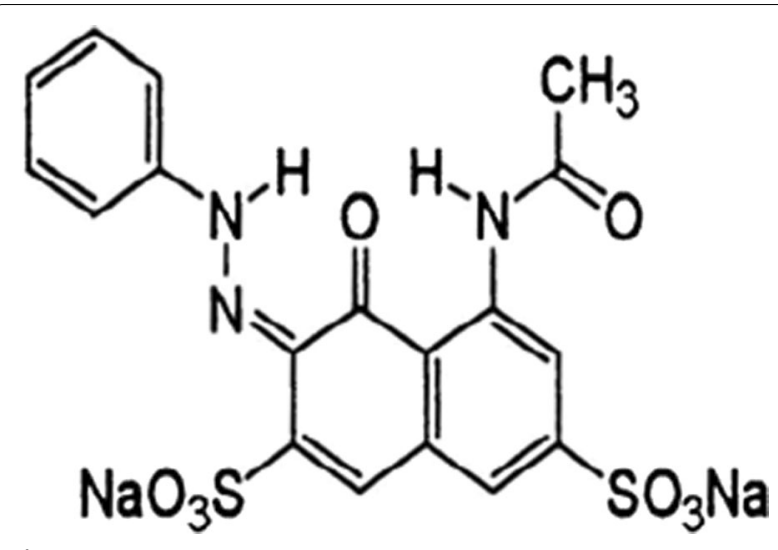

Fig. 1 Dye structure

a dye biosorbent. The used dye Acid Red 1 (AR1) of the structure illustrated in Fig. 1 was purchased from SigmaAldrich Company.

\section{Preparation of biosorbent}

Activation took place by adding $1 \mathrm{~mL}$ of $97 \% \mathrm{H}_{2} \mathrm{SO}_{4}$ drop by drop to $10 \mathrm{~g}$ of RB and kept at room temperature for $24 \mathrm{~h}$. The excess solution was clarified off, while the residue was air-dried and carbonized at $400{ }^{\circ} \mathrm{C}$ for $1 \mathrm{~h}$ in a muffle furnace. The dye solutions were prepared by dissolving a known amount of dye according to the requirements of each experiment (15-50) mg in a 1000-mL measuring flask with deionized double distilled water.

\section{Batch adsorption study}

Batch adsorption experiments were carried out in 1000$\mathrm{mL}$ Erlenmeyer flasks containing $25 \mathrm{~mL}$ of dye solution with scheduled experimental design, and $2 \mathrm{~g}$ of AC. The flasks were agitated using a magnetic stirrer for the required time. After centrifugation at $3000 \mathrm{rpm}$ for $5 \mathrm{~min}$, the remaining dye concentration was measured using UV-Vis spectrophotometer at $600 \mathrm{~nm}$. The adsorption efficiency as a reflection of the dye removal percentage and the adsorption capacity was calculated by Eqs. (1) and (2), respectively (Asfaram et al. 2016):

$$
\begin{aligned}
& \text { Dye Removal\% }=\frac{C_{\mathrm{o}}-C_{\mathrm{f}}}{C_{\mathrm{f}}} \times 100 \\
& q=\frac{C_{\mathrm{o}}-C_{\mathrm{f}}}{X} \times V
\end{aligned}
$$

where $C_{\mathrm{o}}$ is the initial dye concentrations $(\mathrm{mg} / \mathrm{L}), C_{f}$ $(\mathrm{mg} / \mathrm{L})$ is the final dye concentrations $(\mathrm{mg} / \mathrm{L}), q$ is the amount of a dye adsorbed $(\mathrm{mg} / \mathrm{g}), V$ is the solution volume $(\mathrm{L})$, and $X$ is the adsorbent dosage $(\mathrm{g} / \mathrm{L})$.

\section{Experimental design}

The process parameters, namely initial dye concentration $(D), \mathrm{pH}(P)$, and contact time $(T)$, were optimized using response surface method (RSM). The relationship between the parameters and the response was determined using central composite design (CCD) in RSM using Design Expert-6.0.8 software during a trial period. The examined range of the $\mathrm{pH}$ was $3-10$, while the range of dye concentration was $15-50 \mathrm{mg} / \mathrm{L}$, and the range of contact time was 30-110 min. The selected ranges as shown in Table 1 have been chosen based on preliminary experiments. The parameters presented in Table 1 were five levels coded as $-\alpha,-1,0,+1,+\alpha$, respectively. The total number of experiments was 20 with eight factorial points $\left(2^{3}\right)$, six axial points $(2 \times 3)$, and six replicate points according to CCD.

The mathematical relationship between the parameters and the response was to be approximating by the following second-order polynomial model (El-Mekkawi et al. 2019)

$$
\begin{aligned}
Y= & a_{0}+a_{1} X_{1}+a_{2} X_{2}+a_{3} X_{3}+a_{11} X_{1}^{2}+a_{22} X_{2}^{2} \\
& +a_{33} X_{3}^{2}+a_{12} X_{1} X_{2}+a_{13} X_{1} X_{3}+a_{23} X_{2} X_{3}
\end{aligned}
$$

where $Y$ is the predicted response (dye removal \%); $a_{0}$ is the intercept regression constant; $a_{1}, a_{2}, \ldots . a_{23}$ are regression coefficients; and $X_{1}, X_{2}$ and $X_{3}$ are the independent variables investigated. The analysis of variance (ANOVA) was to be performed to justify the significance and fitting of the developed regression model.

\section{Measurements for characterization of the algal biosorbent Fourier transform infrared (FTIR) spectroscopy analysis} The functional groups of $\mathrm{RB}$, the activated de-oiled algae $(A C)$, and those overloaded with dye $(A B)$ were detected using FTIR spectrophotometer Model-JASCO FT/IR-4700 in the infrared spectral range of 400$4000 \mathrm{~cm}^{-1}$ wavelength (Brangule et al. 2020). FTIR figures the information specific to the groups that explain the interactions of the group with the dye molecule.

Table 1 Matrix for the central composite design (CCD)

\begin{tabular}{llllll}
\hline Factors & \multicolumn{1}{l}{ Level } & & & & \\
\cline { 2 - 6 } & Low $(\mathbf{- 1 )}$ & Central (0) & High (+ 1) & $\mathbf{( - \mathbf { a } )}$ & $\mathbf{( + \mathbf { a } )}$ \\
\hline $\begin{array}{l}\text { D: initial dye } \\
\begin{array}{l}\text { Concentration } \\
\text { (mg/L) }\end{array}\end{array}$ & 15 & 32.50 & 50 & 3.07 & 61.93 \\
P: $\mathrm{pH}$ & 3 & 6.50 & 10 & 0.61 & 12.39 \\
T: time (min) & 30 & 70 & 110 & 2.73 & 137.27 \\
\hline
\end{tabular}


Scanning electron microscope (SEM) \& energy-dispersive $X$-ray spectroscopy (EDX)

Morphological analysis was performed using SEM (Model, Joel JAX-480A) with an accelerating voltage of $30 \mathrm{kV}$ and magnification between 10.000X and 400.000X (Ahmed et al. 2019). The EDX unit was used to evaluate the carbon w\% in AC and detect the elements in AB (Sastre de Vicente et al. 2020).

\section{High-resolution transmission electron microscope (TEM)}

The particle sizes of algal biomass samples $\mathrm{RB}$ and $\mathrm{AC}$ were examined under a high-resolution transmission electron microscope [(JEM-1230) JEOL] (Zohoorian et al. 2020).

\section{Results}

The results revealed that the dye removal percent of AR1 is $3.4 \%$ using $\mathrm{RB}$, and it achieved 96\% using AC at the same conditions of operation. These conditions are $15 \mathrm{mg} / \mathrm{L}$ initial dye concentration and $3 \mathrm{pH}$ for $1 \mathrm{~h}$. Therefore, the model describes the relationship between the parameters affecting the dye removal process is applied for AC as biosorbent.

\section{Description and analysis of the model}

The model results for the design points show a significant curvature; thus the axial points are used to fit the model. The quadratic model is selected depending on the statistical results of the suggested model as summarized in Table 2 . The probability F-value revealed that the suggested model is significant, while the error function is not significant. The ANOVA analyses of the quadratic model in Table 3 show that the model terms are the linear factors $(D, P, T)$ and the quadratic factor $P^{2}$. The statistical analyses revealed that the regression coefficient $R^{2}$ is 0.97 and that the adjusted $R^{2}$ is in reasonable agreement with the predicted $R^{2}$. The value of Prob $>F$ is less than 0.05, whereas the lack of fit is not significant.

In addition to the linear relationship of the normal plot of the residuals illustrated in Fig. 2a, the actual values of the response are represented versus the predicted values in Fig. 2b. The data points are spread out from the mean referring to the high variance as the coefficient of variation (C.V.) is greater than one as elucidated in Table 4. Therefore, the model can accurately predict the relationships between the model terms within the selected range. The regression equation in terms of the actual variables is as follows:

Table 2 Suggested model summary statistics

\begin{tabular}{|c|c|c|c|c|c|c|c|c|}
\hline Source & $S^{a}$ & $R^{2}$ & $R^{2} \mathrm{adj}^{\mathrm{b}}$ & $R^{2}$ pred $^{\mathrm{c}}$ & PRESS $^{d}$ & SS Prob $>F^{e}$ & $\begin{array}{l}\text { Lack of fit } \\
\text { Prob }>F^{f}\end{array}$ & \\
\hline Linear & 4.96 & 0.72 & 0.67 & 0.51 & 686.73 & 0.0001 & 0.0020 & \\
\hline $2 \mathrm{~F} 1$ & 5.50 & 0.72 & 0.59 & 0.42 & 820.17 & 0.9999 & 0.0010 & \\
\hline Quadratic & 1.79 & 0.97 & 0.96 & 0.94 & 191.53 & $<0.0001$ & 0.1515 & Suggested \\
\hline Cubic & 1.26 & 0.99 & 0.98 & 0.94 & 193.63 & 0.0816 & 0.5229 & Aliased \\
\hline
\end{tabular}

a Standard deviation

${ }^{\mathrm{b}}$ Adjusted residual squared

' Predicted residual squared

d Predicted residual error sum of squares

e Sequential model sum of the squares probability function

${ }^{f}$ Lack of fit probability function

Table 3 ANOVA results for the CCD

\begin{tabular}{|c|c|c|c|c|c|c|}
\hline Source & Sum of squares & $d f$ & Mean square & $F$ value & Prob $>F$ & \\
\hline Model & 1356.87 & 4 & 339.22 & 109.66 & $<0.0001$ & s \\
\hline$D$ & 876.20 & 1 & 876.20 & 283.25 & $<0.0001$ & $S$ \\
\hline$P$ & 8.93 & 1 & 8.93 & 2.89 & 0.1099 & e \\
\hline$T$ & 125.17 & 1 & 125.17 & 40.46 & $<0.0001$ & s \\
\hline$P^{2}$ & 346.56 & 1 & 346.56 & 112.03 & $<0.0001$ & s \\
\hline Residual & 46.40 & 15 & 3.09 & & & \\
\hline Lack of fit & 37.69 & 10 & 3.77 & 2.16 & 0.2042 & e \\
\hline Pure error & 8.71 & 5 & 1.74 & & & \\
\hline
\end{tabular}

s Significant, e Nonsignificant 

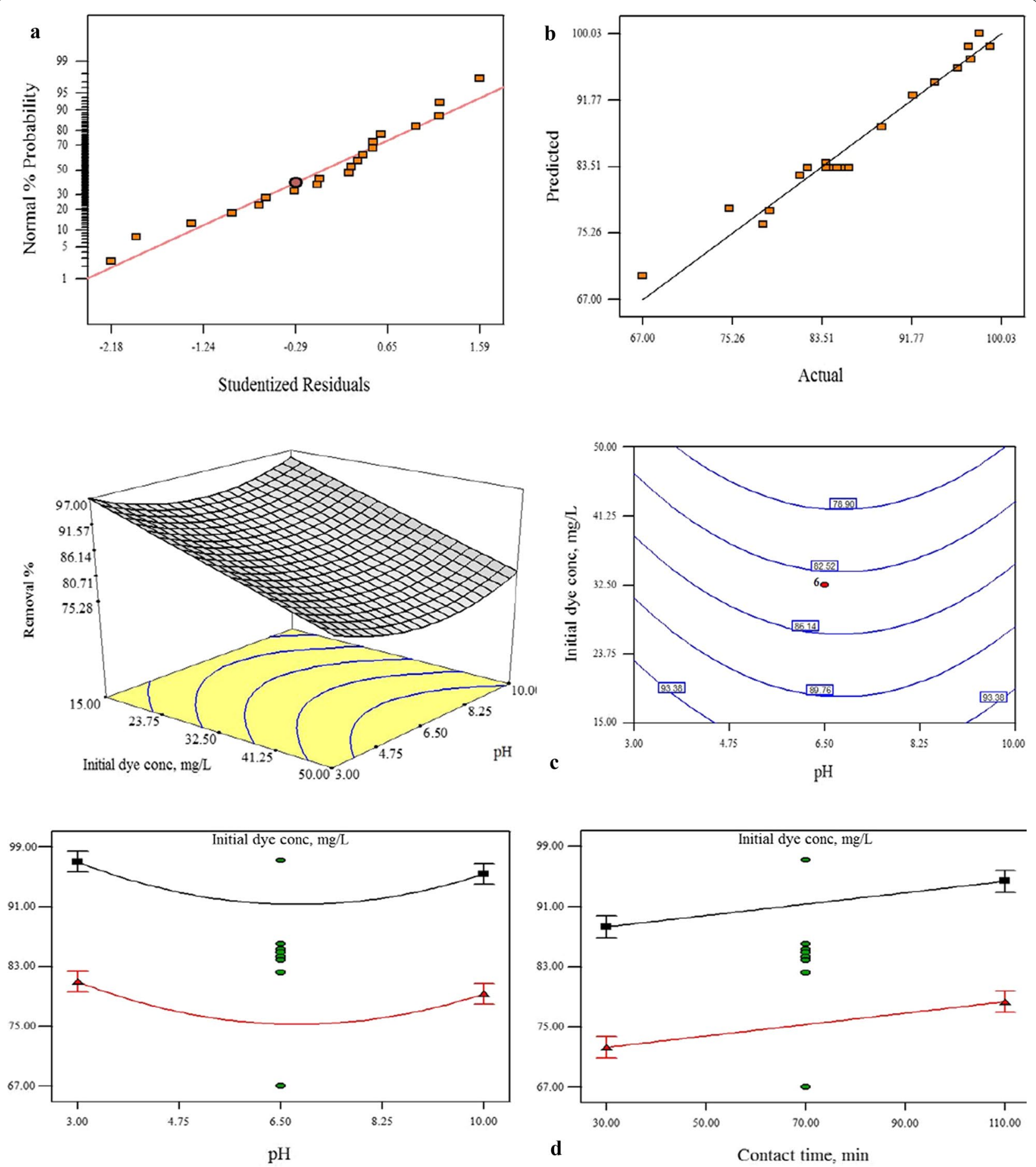

Fig. 2 a Normal plot of the residuals, $\mathbf{b}$ actual values of the response versus the predicted values: $\mathbf{c}$ simultaneous effect of initial dye concentration and effluent $\mathrm{pH}$ on Dye removal \% at the center value of time, and the model contour, $\mathbf{d}$ interaction relationships between the model parameters 
Table 4 Statistical analysis for the response

\begin{tabular}{llllllll}
\hline SD & Mean & CV $^{\mathbf{a}}$ & PRESS & $\boldsymbol{R}^{2}$ & $\boldsymbol{R}^{\mathbf{2}}$ adj & $\boldsymbol{R}^{\mathbf{2}}$ pred & AP $^{\mathbf{b}}$ \\
\hline 1.76 & 86.64 & 2.03 & 79.70 & 0.97 & 0.96 & 0.94 & 34.32 \\
\hline
\end{tabular}

${ }^{\mathrm{a}}$ Coefficient of variation

${ }^{\mathrm{b}}$ Adequate precision

$$
\begin{aligned}
\text { Removal } \%= & 111.1621-0.45771 D-5.38829 P \\
& +0.075686 T+0.39671 P^{2}
\end{aligned}
$$

The model graph and its contour are exhibited in Fig. 2c. It represents the effect of $\mathrm{pH}$ on the model in a parabolic shape that reflects on the contour graph while Fig. $2 \mathrm{~d}$ elucidates the nonexistence of any interaction in the design boundaries.

\section{Optimization of the model solutions}

The actual values of the experimental results are very close to the predicted values of the model; this congruency cause a linear relationship as illustrated in Fig. 2b. Meanwhile, the maximum dye removal percent $98 \%$ is achieved at $15 \mathrm{mg} / \mathrm{L}$ dye concentration, $110 \mathrm{~min}$, and 3 $\mathrm{pH} ; 97 \%$ dye removal is achieved at $10 \mathrm{pH}$. Remarkably, 96\% dye removal is progressed at $32.5 \mathrm{mg} / \mathrm{L}$ initial dye concentration, $12.39 \mathrm{pH}$, and $70 \mathrm{~min}$. The optimization of the three parameters and their response simultaneously is such difficult; therefore, the derived model is the best route for optimization.

The optimization of the model parameters is achieved by defining the priority of each parameter using the Design-Expert software to achieve maximum response. The results of the predicted model revealed that the optimum conditions to achieve $83.5 \%$ dye removal are $37.87 \mathrm{mg} / \mathrm{L}$ initial dye concentration and $3 \mathrm{pH}$ for 30 min. Remarkably, the same results are achieved at $10 \mathrm{pH}$ at a confidence interval of $95 \%$ and a prediction interval of $95 \%$. The adsorption capacity calculated using Eq. 2 is $15.8 \mathrm{mg} / \mathrm{g}$. Contrastingly, for $100 \%$ desirability, the operating conditions are $15 \mathrm{mg} / \mathrm{L}$ initial dye concentration, $\mathrm{pH} \mathrm{3}$, and $110 \mathrm{~min}$ are required to achieve $100 \%$ dye removal. The optimum conditions should consider the priority of treating high concentrations of pollutants at minimum time as discussed in detail in Discussion section.

\section{Characterizations of de-oiled algal biosorbent Fourier transform infrared spectroscopy (FTIR)}

FTIR analysis in Fig. 3 illustrates the functional groups of $\mathrm{RB}, \mathrm{AC}$, and $\mathrm{AB}$. The presence of weak secondary amines $-\mathrm{NH}$ and primary amines $-\mathrm{NH}_{2}$ is proved by the peaks ranging from 3758.58 to $3830.9 \mathrm{~cm}^{-1}$ (Tan et al. 2018; Déniel et al. 2020; Silva et al. 2020). The border absorption peaks at wavelength $3156.90-3275.50 \mathrm{~cm}^{-1}$

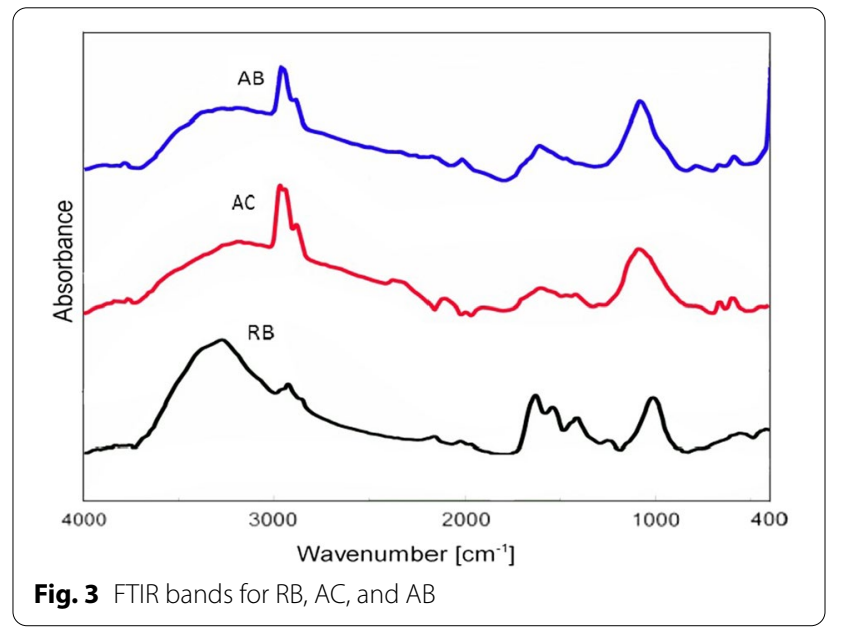

elucidate the existence of stretching hydroxyl group $\mathrm{OH}$ (Kumar et al. 2019) that found in all samples with a higher-intensity value for biosorbent RB.

The stretching $-\mathrm{CH}$ group and aliphatic $-\mathrm{CH}_{2}$ group have a leading role in the adsorption process (Asemani et al. 2020). The peaks at $2924.52-2965.02 \mathrm{~cm}^{-1}$ are exhibiting the presence of $-\mathrm{CH}_{2}$ group with asymmetric stretching in $\mathrm{AC}$ more than $\mathrm{RB}$. The methyl symmetric stretching $-\mathrm{CH}$ group exists in both $\mathrm{AC}$ and $\mathrm{AB}$ at wavelength $2880.17 \mathrm{~cm}^{-1}$.

Sulfur exists as $-\mathrm{SH}$ group at the wavelength $2372.01 \mathrm{~cm}^{-1}$ for sample AC. The $-\mathrm{NO}$ as symmetric stretching vibration group appears at wavelength $1542.77 \mathrm{~cm}^{-1}$ for RB. The nitro group is strongly electron-withdrawing; this elucidates the lower efficiency of $\mathrm{RB}$ than $\mathrm{AC}$ as biosorbent for AR1. The IR spectrum at $1094.4-1092.48 \mathrm{~cm}^{-1}$ is illustrating the $\mathrm{Si}-\mathrm{O}$ group (Asemani et al. 2020).

\section{Scanning electron microscope (SEM)/(EDX)}

Figure 4 illustrates the microstructural and morphological changes in each of $\mathrm{RB}, \mathrm{AC}$, and $\mathrm{AB}$ algal biomass that was analyzed using scanning electron microscopy (SEM). The shape of RB shows a smooth and irregular surface with random heterogeneous sizes. The surface of AC has a regular and small homogeneous size that increases the surface area and ultimately enhanced its adsorption capacity. On the other hand, the $\mathrm{AB}$ has elongated regular fiber bundles with a smooth distinct surface. The 
carbon w\% is measured and examined using EDX analysis. The most significant result is the increase of carbon w\% in AC by $29 \%$.

\section{Transmission electron microscope (TEM)}

The results of TEM illustrated that the particle size of the used RB is over $200 \mathrm{~nm}$ as illustrated in Fig. 5 while the particle size of AC is in the range of $12-31 \mathrm{~nm}$. This analysis is used to figure the effect of activation process that enhances reduction of the particle size. This contributes in explanation of the wide difference between $\mathrm{RB}$ and $\mathrm{AC}$ performance as biosorbent.

\section{Eco-friendly environmental disposal of wastes:}

EDX analysis detected several elements in $\mathrm{AB}$ as illustrated in Fig. 6. These elements as $\mathrm{C}, \mathrm{O}, \mathrm{Na}, \mathrm{Si}, \mathrm{P}, \mathrm{S}$, and $\mathrm{Ca}$ are mixed to agricultural soil as shown in Fig. 6 . The plant growing in soil mixed with $\mathrm{AB}$ samples is significant. This prospective function of over-loaded biomass as
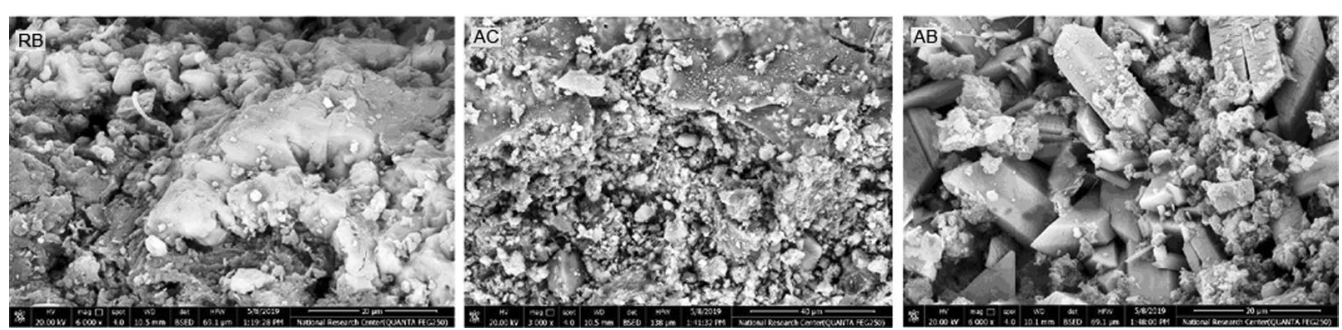

Fig. 4 SEM images of $R B, A C$, and $A B$
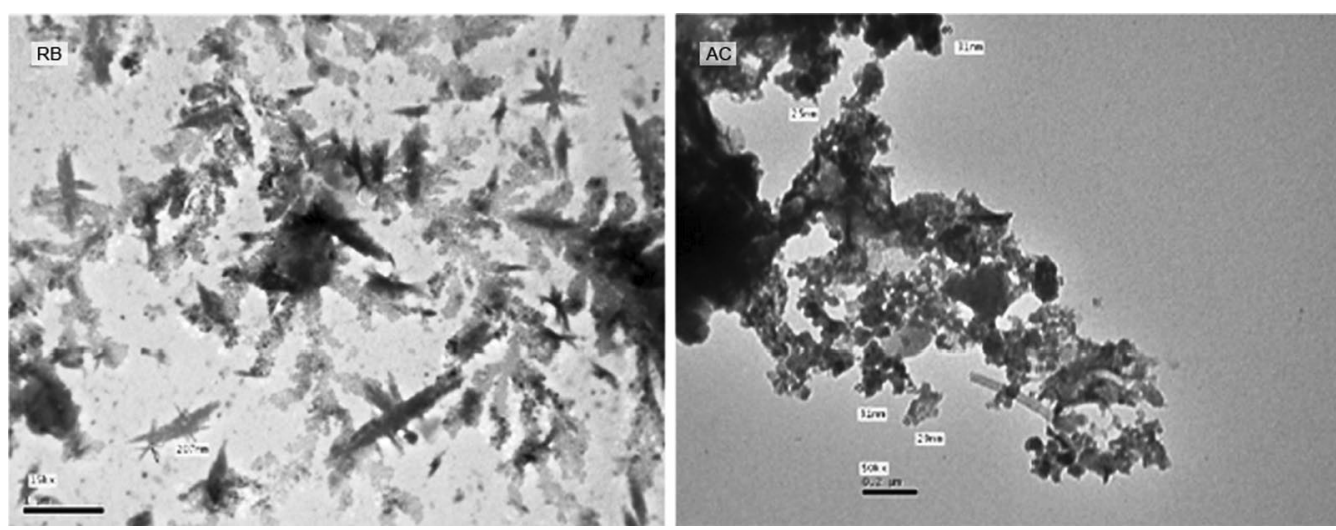

Fig. 5 TEM images of $R B$, and $A C$
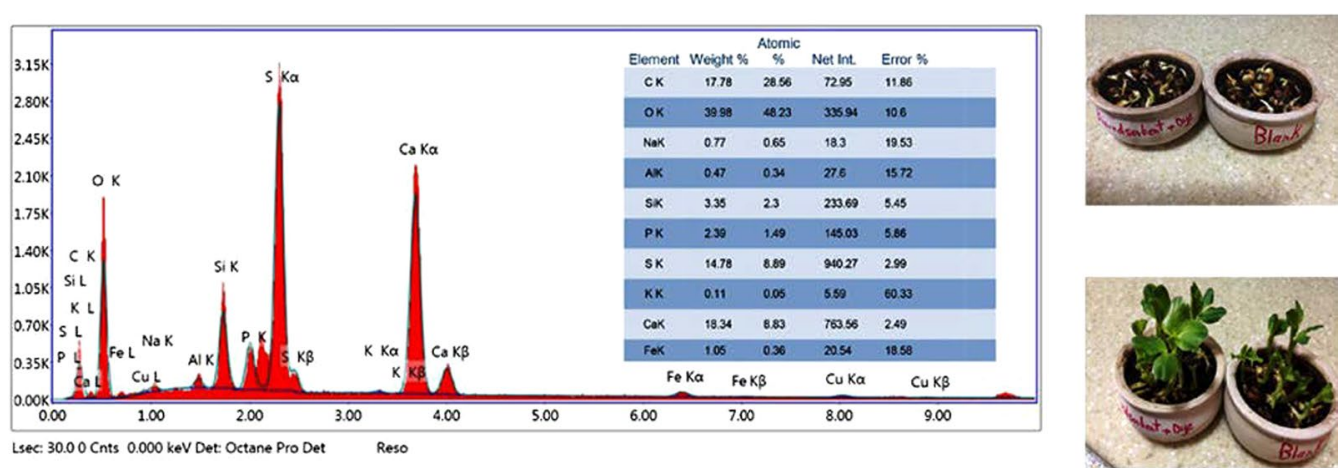

Fig. 6 Elemental analysis for $A B$ using EDX and its reflection on plant 
micro-nutrients for agricultural soil needs more study for a long period with further analyses.

\section{Discussion}

\section{Description and analysis of the model}

The quadratic model is selected depending on the model summary statistics in Table 2. The cubic model is aliased, which prevents the proper navigation and transformation for the cubic model. Meanwhile, the quadratic model has the maximum values of $R^{2}$, Adj. $R^{2}$, and Pred. $R^{2}$; they are $0.97,0.96$, and 0.94 , respectively. It also has a minimum PRESS value that indicates the predictive ability of the model. The probability function of the model elucidated Prob $>F$ smaller than 0.05 for both linear and polynomial models. However, the sequential sum of squares favors the highest order polynomial, where the additional terms are significant and the model is not aliased while the probability function of the lack of fit is significant for both linear and factorial models that elucidate high error for both.

In Table 3, the model $F$ value of 109.66 implies the model is significant. The model terms $D, T, P^{2}$ are significant for Prob $>F$ smaller than 0.05. Despite the term $P$ is not significant, it is required to support hierarchy. In Table 4, the adequate precision ratio of 34.32 indicates an adequate signal-to-noise ratio that elucidates that this model can be used to navigate the design space. The coefficients of the actual factors in the model equation are to be displayed in six decimal places without any approximation; this action is necessary to justify the required accuracy as much as possible.

The normal probability plot of the studentized residuals is illustrated in Fig. 2a elucidates the normality of residuals distribution. The actual values of experiments versus the predicted values through the model calculations in Fig. $2 \mathrm{~b}$ are very close using linear regression. The model graph and its contour in Fig. 2c represents the effect of the term $P^{2}$ on the response. Either low or high $\mathrm{pH}$ reflects increasing the percent removal, while neutrality exists at the vertex point. The absence of interaction between the parameters as illustrated in Fig. 2d emphasizes the ability of the model to navigate the design space.

The main target of developing the predicting model is to optimize the process parameters to achieve maximum the percent removal. Thus, the highest importance has been given to the response, followed by the process parameters. The logical goal is to treat maximum dye concentration during the minimum time, whereas neutral solutions have a lower response than acidic and ones alkaline, i.e., $\mathrm{pH}$ has lower importance. The lower response area, as shown in the 3D model graph Fig. 2c and its contour, is located at the bottom of the convex while the response increases through navigation the curve from neutral $\mathrm{pH}$ towards acidic or alkaline region. Contrastingly, the desirability function to approach $100 \%$ dye removal results in having to change operating conditions to be the lowest boundary of the model limits for initial dye concentration and $\mathrm{pH}$, and the highest limits for time. This approach decreased the adsorption capacity by half while increasing the water purification by $17 \%$. Particularly, selecting a specific approach should follow the industrial requirements and the environmental aspects.

\section{Characteristics of de-oiled biosorbent}

FTIR analysis contributes to the explanation of biosorption mechanism through the description of their functional group. The presence of secondary amines $-\mathrm{NH}$ and primary amines $-\mathrm{NH}_{2}$ in $\mathrm{RB}$, and $\mathrm{AC}$ clarified the ability of algal biosorbent to form the positive cations performing ionic pond with AR1 ions (Tan et al. 2018; Déniel et al. 2020; Silva et al. 2020). The stretching ponds in the $-\mathrm{CH}$ group and aliphatic $-\mathrm{CH}_{2}$ group have a central role in the adsorption process as they possess a high ability to form free radicals that attract the AR1 ions (Asemani et al. 2020). The increasing of carbon w\% in AC detected by EDX emphasizes the presence of an aliphatic $\mathrm{CH}_{2}$ group and stretching $\mathrm{CH}$ group in $\mathrm{AC}$.

SEM analysis illustrates the change in the microstructure of $\mathrm{AC}$ and $\mathrm{AB}$. The regular and small homogeneous size of $A C$ increases the surface area and ultimately enhanced its adsorption capacity while the elongated regular fiber bundles with a smooth distinct surface of $\mathrm{AB}$ elucidate the adsorption process for the surface and the core absorption inside the biosorbent particle.

The reduction of nanoparticle size of $\mathrm{AC}$, as figured by TEM analysis, increases the active sites and encourages rapid contact between the dye molecules and the binding sites (Zohoorian et al. 2020). This analysis explains the wide variation in $R B$ and $A C$ performance as the dye removal percent using $\mathrm{RB}$ and $\mathrm{AC}$ are $3.4 \%$, and $96 \%$, respectively. These results are integrated with that detected by SEM analysis, where the morphology and the homogeneous shape of AC facilitate the dye removal.

The desorption process is necessary to complete the process cycle. However, several obstacles contradict this process; some of them are related to the cost and the other is related to the environment (Farooq et al. 2018). The minor elements included in such material enhance its potentiality to be used as a micro-nutrient for agricultural soil. Further research has to be performing to cover the plant requirements and human health. 


\section{Conclusions}

The recent research is concerned with applying microorganisms in dye removal from textile wastewater. Microalgae are a potential source for several industries. The extracted oil from $C$. vulgaris is suitable for biofuel and biomedical. Thus; using de-oiled microalgae in integrated industries enhance its potentiality. The activation process transforms the biomass surface into a regular and small homogeneous size that increases the surface area and ultimately enhances its adsorption capacity. The simultaneous optimization of the process parameters is achieved by CCD in RSM. This method decreases the number of essential experiments and provides a predicting model with a CI of 95\%. Further experiments are encouraged to be performing to study more process parameters as the AC amount and process temperature. The reusability of dye-loaded bio sorbent as micro-nutrient is an important economical aspect to avoid the obstacles of the desorption process and provide a useful by-product.

\begin{abstract}
Abbreviations
AB: Dye-loaded biomass; AC: Activated de-oiled microalgae; AR1: Acid Red 1 dye; ANOVA: Analysis of variance-statistics; CCD: Central composite design; $\mathrm{Cl}$ : Confidence interval; CV: Coefficient of variance; EDX: Energy-dispersive X-ray analysis; FTIR: Fourier transform infrared spectroscopy; RB: De-oiled microalgae; RSM: Response surface method; SEM: Scanning electron microscopy; TEM: Transmission electron microscope.
\end{abstract}

\section{Acknowledgements}

This paper was supported by the National Research Centre in Egypt; we highly appreciate the central laboratories for conducting the tests in this research.

\section{Authors' contributions}

"SA Abo El-Enin and RA conceptualized the main idea of this work. SA Abo EI-Enin and SA El-Mekkawi prepared the de-oiled activated carbon. RA and FA performed the characterization analyses of the biosorbent and the dye adsorption experiments. SA El- Mekkawi performed the statistical analysis of the CCD; she is also the corresponding author. All authors contributed to writing the manuscript. All authors read and approved the final manuscript.

\section{Funding}

The National Research Centre, Dokki, Egypt, has provided this research a financial support Grant Number "12010203".

\section{Availability of data and materials}

All data generated or analyzed during this study are included in this published article [and its supplementary information files].

\section{Declarations}

Ethics approval and consent to participate

Not applicable.

\section{Consent for publication}

Not applicable.

\section{Competing interests}

The authors declare that they have no competing interests.

\section{Author details}

${ }^{1}$ Chemical Engineering and Pilot Plant Department, Engineering Research Division, National Research Centre, P.O. 12622, Giza, Egypt. ²Dyeing, Printing and Textile Auxiliaries Department, Textile Industries Research Division, National Research Centre, P.O. 12622, Giza, Egypt.

Received: 22 February 2021 Accepted: 14 April 2021

Published online: 23 April 2021

\section{References}

Abdulrazzaq NN, Al-Sabbagh BH, Shanshool HA (2021) Coupling of electrocoagulation and microflotation for the removal of textile dyes from aqueous solutions. J Water Process Eng 40:101906. https://doi.org/10.1016/j. jwpe.2020.101906

Adeogun Al, Akande JA, Idowu MA, Kareem SO (2019) Magnetic tuned sorghum husk biosorbent for effective removal of cationic dyes from aqueous solution: isotherm, kinetics, thermodynamics and optimization studies. Appl Water Sci 6:160. https://doi.org/10.1007/s13201-019-1037-2

Ahmed EA, Abo Elenin S, Mahamoud H (2019) Solvent extraction techniques of lipid from algal species in wastewater treatment station. Eygpt J Chem 62(8):1551-1562. https://doi.org/10.21608/EJCHEM.2019.7862.1618

Asemani M, Rabbani AR, Sarafdokht H (2020) Evaluation of oil fingerprints similarity by a novel technique based on FTIR spectroscopy of asphaltenes: modified moving window correlation coefficient technique. Mar Pet Geol 120:104542. https://doi.org/10.1016/j.marpetgeo.2020.104542

Asfaram A, Ghaedi M, Ghezelbash GR, Dil EA, Tyagi I, Agarwal S et al (2016) Biosorption of malachite green by novel biosorbent Yarrowia lipolytica isf7: application of response surface methodology. J Mol Liq 214:249-258. https://doi.org/10.1016/j.molliq.2015.12.075

Berradi M, Hsissou R, Khudhair M, Assouag M, Cherkaoui O, El Bachiri A et al (2019) Textile finishing dyes and their impact on aquatic environs. Heliyon 5(11):e02711. https://doi.org/10.1016/j.heliyon.2019.e02711

Brangule A, Šukele R, Bandere D (2020) Herbal medicine characterization perspectives using advanced FTIR sample techniques - diffuse reflectance (DRIFT) and photoacoustic spectroscopy (PAS). Front Plant Sci 11:356. https://doi.org/10.3389/fpls.2020.00356

Cheng Z, Feng KE, Su Y, Ye J, Chen D, Zhang S et al (2020) Novel biosorbents synthesized from fungal and bacterial biomass and their applications in the adsorption of volatile organic compounds. Bioresour Technol 300:122705. https://doi.org/10.1016/j.biortech.2019.122705

Chew KW, Shiong Khoo K, Thung Foo H, Reen Chia Sh, Walvekar R, Shee LS (2021) Algae utilization and its role in the development of green cities. Chemosphere 268:129322. https://doi.org/10.1016/j.chemosphere.2020. 129322

da Silva PC, de Oliveira Neto GC, Ferreira Correia JM, Pujol Tucci HN (2021) Evaluation of economic, environmental and operational performance of the adoption of cleaner production: survey in large textile industries. J Clean Prod 278:123855. https://doi.org/10.1016/j.jclepro.2020.123855

de Oliveira Neto GC, Pujol Tucci HN, Ferreira Correia JM, da Silva PC, da Silva D, Amorim M (2021) Stakeholders'influences on the adoption of cleaner production practices: a survey of the textile industry. Sustain Prod Consum 26:126-145. https://doi.org/10.1016/j.spc.2020.10.001

Déniel M, Lagarde F, Caruso A, Errien N (2020) Infrared spectroscopy as a tool to monitor interactions between nanoplastics and microalgae. Anal Bioanal Chem 412:4413-4422. https://doi.org/10.1007/s00216-020-02683-9

El-Mekkawi SA, Abdo SM, Samhan FA, Ali GH (2019) Optimization of some fermentation conditions for bioethanol production from microalgae using response surface method. Bull Natl Res Cent 43(1):164. https://doi.org/10. 1186/s42269-019-0205-8

Farooq M, Almustapha MN, Imran M, Saeed MA, Andresen JM (2018) In-situ regeneration of activated carbon with electric potential swing desorption (EPSD) for the $\mathrm{H}_{2} \mathrm{~S}$ removal from biogas. Bioresour Technol 249:125-131. https://doi.org/10.1016/j.biortech.2017.09.198

Heffron R, Körner MF, Wagner J, Weibelzahl M, Fridgen G (2020) Industrial demand-side flexibility: a key element of a just energy transition and industrial development. Appl Energy 269:1 15026. https://doi.org/10. 1016/j.apenergy.2020.115026

Khalifa EB, Rzig B, Chakroun R, Nouagui H, Hamrouni B (2019) Application of response surface methodology for chromium removal by adsorption on low-cost biosorbent. Chemometr Intell Lab Syst 189:18-26. https://doi. org/10.1016/j.chemolab.2019.03.014 
Khorasani AC, Shojaosadati SA (2019) Magnetic pectin-Chlorella vulgaris biosorbent for the adsorption of dyes. J Environ Chem Eng 7(3):103062. https://doi.org/10.1016/j.jece.2019.103062

Kishor R, Purchase D, Saratale GD, Saratale RG, Romanholo Ferreira LF, Bilal M, Chandra R, Bharagava RN (2021) Ecotoxicological and health concerns of persistent coloring pollutants of textile industry wastewater and treatment approaches for environmental safety. J Environ Chem Eng 9(2):105012. https://doi.org/10.1016/j.jece.2020.105012

Kumar S, Ahluwalia AS, Charaya MU (2019) Adsorption of Orange-G dye by the dried powdered biomass of Chlorella vulgaris Beijerinck. Curr Sci 116(4):604-611. https://doi.org/10.18520/cs/v116/i4/604-611

Lellis B, Fávaro-Polonio C, Pamphile J, Polonio J (2019) Effects of textile dyes on health and the environment and bioremediation potential of living organisms. Biotechnol Res Innov 3:275-290. https://doi.org/10.1016/j. biori.2019.09.001

Liang Z, Wang J, Zhang Y, Han C, Ma S, Chen J et al (2020) Removal of volatile organic compounds (VOCs) emitted from a textile dyeing wastewater treatment plant and the attenuation of respiratory health risks using a pilot-scale biofilter. J Clean Prod 253:120019. https://doi.org/10.1016/j. jclepro.2020.120019

Liu Z, Ren B, Ding H, He H, Deng H, Zhao C et al (2020) Simultaneous regeneration of cathodic activated carbon fiber and mineralization of desorbed contaminations by electro-peroxydisulfate process: advantages and limitations. Water Res 171:115456. https://doi.org/10.1016/j.watres.2019. 115456

Mansor ES, Ali H, Abdel-Karim A (2020) Efficient and reusable polyethylene oxide/polyaniline composite membrane for dye adsorption and filtration. Colloids Interface Sci Commun 39:100314. https://doi.org/10.1016/j. colcom.2020.100314

Ribeiro JS, Veloso CM (2021) Microencapsulation of natural dyes with biopolymers for application in food: a review. Food Hydrocoll 112:106374. https://doi.org/10.1016/j.foodhyd.2020.106374

Sastre de Vicente ME, Rodriguez-Barro P, Herrero R, Vilariño T, Lodeiro P, Barriada JL (2020) Biosorption of chemical species by Sargassum algal biomass: equilibrium data. In: Konur O (ed) Handbook of algal science, technology and medicine. Academic Press, pp 675-696. https://doi.org/ 10.1016/B978-0-12-818305-2.00042-5

Semião MA, Isidoro Haminiuk CW, Maciel GM (2020) Residual diatomaceous earth as a potential and cost effective biosorbent of the azo textile dye Reactive Blue 160. J Environ Chem Eng 8(1):103617. https://doi.org/10. 1016/j.jece.2019.103617

Shen C, Pan Y, Wu D, Liu Y, Ma C, Li F et al (2019) A crosslinking-induced precipitation process for the simultaneous removal of poly(vinyl alcohol) and reactive dye: the importance of covalent bond forming and magnesium coagulation. Chem Eng J 374:904-913. https://doi.org/10.1016/j.cej.2019. 05.203

Silva A, Coimbra RN, Escapa C, Figueiredo SA, Freitas OM, Otero M (2020) Green microalgae Scenedesmus obliquus utilization for the adsorptive removal of nonsteroidal anti-inflammatory drugs (NSAIDs) from water samples. Int J Environ Res 17:3707. https://doi.org/10.3390/ijerph1710 3707

Soylu M, Gökkuş O, Özyonar F (2020) Foam separation for effective removal of disperse and reactive dyes from aqueous solutions. Sep PurifTechnol 247:116985. https://doi.org/10.1016/j.seppur.2020.116985
Suganya E, Saranya N, Sivaprakasam S, Varghese LA, Narayanasamy S (2020) Experimentation on raw and phosphoric acid activated Eucalyptus camadulensis seeds as novel biosorbents for hexavalent chromium removal from simulated and electroplating effluents. Environ Technol Innov 19:100977. https://doi.org/10.1016/j.eti.2020.100977

Suhas GVK, Singh LP, Chaudhary M, Kushwaha S (2021) A novel approach to develop activated carbon by an ingenious hydrothermal treatment methodology using Phyllanthus emblica fruit stone. J Clean Prod 288:125643. https://doi.org/10.1016/j.jclepro.2020.125643

Taer E, Yusra DA, Amri A et al (2021) The synthesis of activated carbon made from banana stem fibers as the supercapacitor electrodes. Mater Today Proc. https://doi.org/10.1016/j.matpr.2020.11.645

Tan XB, Lam MK, Uemura Y, Lim JW, Wong CY, Ramli A et al (2018) Semi-continuous cultivation of Chlorella vulgaris using chicken compost as nutrients source: growth optimization study and fatty acid composition analysis. Energy Convers Manag 164:363-373. https://doi.org/10.1016/j.encon man.2018.03.020

Tang Y, Zhang Z, Yang S, Smith GJ, Liu L (2021) Diatomite encapsulated AgNPs as novel hair dye cosmetics: preparation, performance, and toxicity. Colloid Surf B Biointerfaces. https://doi.org/10.1016/j.colsurfb.2021.111599

Venkataraghavan R, Thiruchelvi R, Sharmila D (2020) Statistical optimization of textile dye effluent adsorption by Gracilaria edulis using Plackett-Burman design and response surface methodology. Heliyon 6(10):e05219. https:// doi.org/10.1016/j.heliyon.2020.e05219

Wang Y, Sun X, Han Q, James TD, Wang X (2021) Highly sensitive and selective water-soluble fluorescent probe for the alternative detections of formaldehyde in leather products. Dyes Pigm. https://doi.org/10.1016/j.dyepig. 2021.109175

Watari T, Hata Y, Hirakata Y, Nguyet PN, Nguyen YH, Maki S et al (2021) Performance evaluation of down-flow hanging sponge reactor for direct treatment of actual textile wastewater: effect of effluent recirculation to performance and microbial community. J Water Process Eng 39:101724. https://doi.org/10.1016/j.jwpe.2020.101724

Yeddou-Mezenner N (2010) Kinetics and mechanism of dye biosorption onto an untreated antibiotic waste. Desalination 262(1-3):251-259. https://doi. org/10.1016/j.desal.2010.06.023

Zhang C, Cheng F, Zhao H, Li J (2020) Enhanced phenol degradation under different shock-stress in LAC/AS system: the combination effects of LAC toxicity mitigation and microbial community shift. J Water Process Eng. https://doi.org/10.1016/j.jwpe.2020.101824

Zohoorian H, Ahmadzadeh H, Molazadeh M, Shourian M, Lyon S (2020) Microalgal bioremediation of heavy metals and dyes. In: Konur O (ed) Handbook of algal science, technology and medicine. Academic Press, pp 659-674. https://doi.org/10.1016/B978-0-12-818305-2.00041-3

\section{Publisher's Note}

Springer Nature remains neutral with regard to jurisdictional claims in published maps and institutional affiliations.

\section{Submit your manuscript to a SpringerOpen ${ }^{\circ}$ journal and benefit from:}

- Convenient online submission

- Rigorous peer review

- Open access: articles freely available online

- High visibility within the field

- Retaining the copyright to your article

Submit your next manuscript at springeropen.com 